\title{
The Plot Thickens, Gelation by Phenylalanine in Water and Dimethyl Sulfoxide
}

\author{
Karol P. Nartowski,[a] Susana M. Ramalhete,[a] Peter C. Martin,[b] Jamie S. Foster, [c]
}

Margaux Heinrich,[c] Mark D. Eddleston,[b] Hayley R. Green,[c] Graeme M. Day,[d] Yaroslav

Z. Khimyak $[a] *$ and Gareth O. Lloyd $[b][c] *$.

[a] School of Pharmacy, University of East Anglia, Norwich, United Kingdom, NR4 7TJ, Email:Y.Khimyak@uea.ac.uk

[b] Department of Chemistry, Cambridge University, Lensfield Road, Cambridge, United Kingdom, CB2 1EW

[c] Institute of Chemical Sciences, School of Engineering and Physical Sciences, Heriot-Watt University, Edinburgh, Scotland, United Kingdom, EH14 4AS, E-mail: G.O.Lloyd@hw.ac.uk [d] School of Chemistry, Southampton University, Southampton, United Kingdom SO17 1BJ

KEYWORDS: phenylalanine, gel, LMWG, self-assembly, crystallisation, crystal structure prediction, CSP, NMR crystallography

\footnotetext{
ABSTRACT: Phenylalanine (Phe) is an amino acid of great interest as coupling of an aromatic group with a chiral hydrophilic region imparts a number of unique properties. Recently there has been an increased interest in the crystalline and gel forms of this compound, part as a result of the
} 
complex and undetermined structures of the resulting materials and the relationship of the solid forms of Phe with the disease phenylketonuria. In this report, we highlight the relationship between gelation, crystallisation and the dynamics of self-assembly processes of Phe. We do this by describing the gelation of the amino acid, the gel to crystal relationship, crystal structure predictions for this relatively simple compound and the dynamics of assembly as determined by NMR in both water and dimethyl sulfoxide. This will provide guidance to future research into Phe assemblies, possible treatments for phenylketonuria and diseases related to formation of amyloidlike fibres.

\section{INTRODUCTION}

L-Phenylalanine (Phe), the quintessential aromatic amino acid, is one of the key building blocks of life. Within humans, the metabolism of this compound is crucial and when this does not work quite right it leads to the disease phenylketonuria. The assembly of fibres by Phe has been linked to the process of tissue damage in the disease. ${ }^{1-4}$ The metabolites of Phe include DOPA, tyrosine and endocrine hormones. ${ }^{5}$ The phenylketonuria condition explains why many food products are labelled "may contain a source of phenylalanine". Within the industry, this amino acid is a key starting material for the synthesis of many important products such as the sweetener aspartame. ${ }^{6,7}$ Astonishingly, it is only within the $21^{\text {st }}$ century that a more complete understanding of the crystalline and amorphous solid forms of this material has started to reveal their true and complex behaviour. ${ }^{8-15}$ This is not to belittle the scientific observations of the previous centuries, it has been well recognised that it is "difficult to crystallise single crystals" and the capability of modern instrumentation is considerably better. ${ }^{16-18}$ During the initial period in which we started to study the gelation of Phe, a careful literature search revealed an intriguing paper by Myerson referring 
to a "gel-crystallisation". ${ }^{6}$ The description of what appears to be a hydrogel was considerably interesting, and clearly a different gelation behaviour to the gelation within the solvent DMSO, which initially sparked our research program. More recently, Gazits' and co-workers reported on the fibre formation within the diseased tissue related to phenylketonuria. ${ }^{1,8}$ The work clearly showed that the fibres are crystalline in nature. This work also hinted that Phe self-assembly in water was related to the disease and that fibre formation was important.

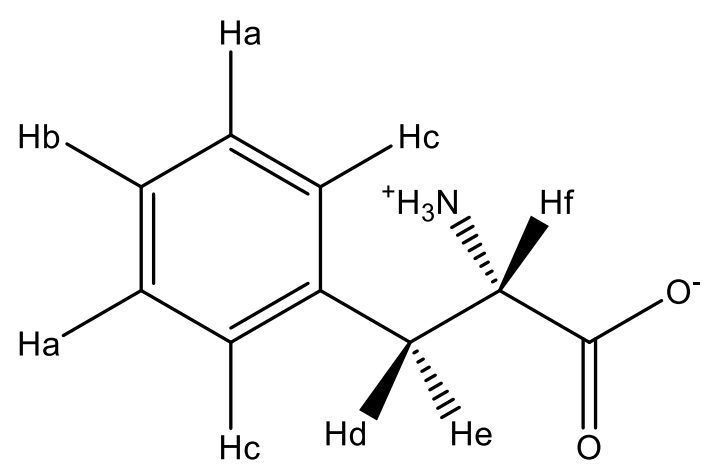

Scheme 1. L-Phenylalanine (Phe) was utilised throughout this study. As a result, Phe in this manuscript refers to the enantiomerically pure compound. Labels are utilised in the NMR descriptions.

Related to this were the crystallographic studies determining the significant number of structure forms of Phe crystalline solids by the groups of Harris, Gazit, Korter and Görbitz. ${ }^{8-11}$ Through some very attentive powder and single crystal diffraction studies coupled to computational work, they have shown the existence of a total of seven solid forms (4 polymorphs, two hydrates and a racemic solid form). Most recently, while preparing this manuscript, a report from Thakur and coworkers discussing gelation of Phe in water, its kinetics and disruption by racemic crystallisation was published. ${ }^{4}$ There are even reports of gelation of Phe with metals such as copper. ${ }^{19}$ These 
reports clearly show the true atomic crystallographic structures of a number of polymorphs and hydrate crystalline materials as well as the fibre formation by Phe in water. All of these are important and of interest to not only medicine (phenylketunoria) and biology, but also chemists and materials scientists. All these studies corroborated our interest in the gelation phenomena of Phe and focused the need to establish the linkage between the crystal solid forms and the gel fibresolid forms of Phe. What follows is the description of the gels in water and in DMSO (the first report of this gelation), the crystalline forms related to the hydrogelation, crystal structure prediction of Phe, ${ }^{20-26}$ and NMR studies to elucidate structure and dynamics of the water and DMSO based materials, and the comparison between the different gels.

\section{EXPERIMENTAL SECTION}

\section{MATERIALS}

Chemicals were purchased from the following chemical companies and used without further purification: $L$-phenylalanine (Phe) - Sigma Aldrich; DMSO - Fisher; deuterated solvents $\left(\mathrm{D}_{2} \mathrm{O}\right.$, DMSO-d6) - Goss Scientific; ${ }^{13} \mathrm{C},{ }^{15} \mathrm{~N}$ labelled $L$-phenylalanine - Cortecnet.

\section{METHODS}

\section{Gelation procedures}

Both sets of gels are thermoreversible or heat set gels. Gelation tests were performed by dissolving Phe in DMSO (dry) or distilled water in screw cap glass vials under a heat gun.

\section{Single Crystal Diffraction, Powder Diffraction and Crystallography}

Crystal data for phenylalanine monohydrate [CCDC Number 1532251]: $\mathrm{C}_{9} \mathrm{H}_{13} \mathrm{NO}_{3}, M=183.20$, clear colorless needle, $0.3 \times 0.2 \times 0.05 \mathrm{~mm}^{3}$, monoclinic, space group $P 2_{1}$ (No. 4 ), $V=957.11(17)$ $\AA^{3}, Z=4, D_{\mathrm{c}}=1.271 \mathrm{~g} / \mathrm{cm}^{3}, F_{000}=392$, Bruker APEX-II CCD, MoK $\alpha$ radiation, $\lambda=0.71073 \AA$, $T=100 \mathrm{~K}, 2 \theta_{\max }=56.9^{\circ}, 5701$ reflections collected, 3261 unique $\left(\mathrm{R}_{\text {int }}=0.0355\right)$. The structure 
was solved and refined using the programs SHELXS ${ }^{27}$ and ShelXL,${ }^{27}$ respectively. The program X-Seed ${ }^{28}$ was used as an interface to the SHELX programs, and to prepare the figures. Final GooF $=0.984, R 1=0.0467, w R 2=0.0810, R$ indices based on 2270 reflections with $\mathrm{I}>2(\mathrm{I})$ (refinement on $F^{2}$ ), 250 parameters, 5 restraints. Lp and absorption corrections applied, $\mu=0.096 \mathrm{~mm}^{-1}$. Absolute structure parameter $=0.3(10) .^{29}$

Crystal data for phenylalanine hemihydrate [CCDC Number 1532250]: $\mathrm{C}_{9} \mathrm{H}_{12} \mathrm{NO}_{2.5}, M=174.20$, colourless needle, $0.4 \times 0.09 \times 0.01 \mathrm{~mm}^{3}$, monoclinic, space group $P 2_{1}$ (No. 4), $a=12.0057(9), b$ $=5.4230(4), c=13.6685(12) \AA, \beta=100.981(9)^{\circ}, V=873.62(12) \AA^{3}, Z=4, D_{\mathrm{c}}=1.324 \mathrm{~g} / \mathrm{cm}^{3}, F_{000}$ $=372$, Xcalibur, Eos, Gemini ultra, $\mathrm{Cu} \mathrm{K} \alpha$ radiation, $\lambda=1.5418 \AA, T=119.95(10) \mathrm{K}, 2 \theta_{\max }=$ $142.9^{\circ}, 3872$ reflections collected, 2301 unique $\left(\mathrm{R}_{\text {int }}=0.0456\right)$. The structure was solved and refined using the programs SHELXS ${ }^{27}$ and ShelXL, ${ }^{27}$ respectively. The program X-Seed ${ }^{28}$ was used as an interface to the SHELX programs, and to prepare the figures. Final $G o o F=1.099, R 1$ $=0.0875, w R 2=0.2595, R$ indices based on 2094 reflections with $\mathrm{I}>2$ sigma(I) (refinement on $F^{2}$ ), 230 parameters, 4 restraints. Lp and absorption corrections applied, $\mu=0.801 \mathrm{~mm}^{-1}$.

\section{Hirshfeld analysis}

Electrostatic potential Hirshfeld surface calculated using CrystalExplorer with Tonto. DFT calculation with 6-311G $(\mathrm{d}, \mathrm{p})$ basis set with Becke88 exchange potential and LYP correlation potential.

\section{Rheology}

Rheological experiments were performed on a Bohlin nano II rheometer. All samples were collected using a gap of $150 \mu \mathrm{m}$ gap and a solvent trap.

\section{a. Phenylalanine hydrogel}


The rheometer was equipped with a $40 \mathrm{~mm}$ stainless steel cone $\left(4^{\circ}\right)$. Gels for rheological analysis were formed as follows. In a sealed vial containing $2 \mathrm{ml}$ of deionised water the appropriate amount of Phe was dissolved with the aid of heating. Once fully dissolved the solution was injected into the gap between the cone and the rheometer's plate $\left(50^{\circ} \mathrm{C}\right)$ using a warm syringe. Once the solution was in place the plate was gradually cooled to $20^{\circ} \mathrm{C}$ and left for $1 \mathrm{~h}$ to allow the gel to form.

\section{b. Phenylalanine organogel}

The rheometer was equipped with a $40 \mathrm{~mm}$ acrylic plate. Gels for rheological analysis were formed as follows. In a sealed vial containing $2 \mathrm{ml}$ of DMSO the appropriate amount of Phe was dissolved with the aid of heating. Once fully dissolved the solution was injected into the gap between the acrylic and the rheometer's plate $\left(50^{\circ} \mathrm{C}\right)$ using a warm syringe. Once the solution was in place the plate was gradually cooled to $20^{\circ} \mathrm{C}$ and left for $1 \mathrm{~h}$ to allow the gel to form.

\section{Scanning electron microscopy}

SEM images were produced using a Philips XL30 LaB6 ESEM equipped with an Oxford Instrument X-max $80 \mathrm{EDX}$ detector at $3 \mathrm{kV}$. Wet gel samples were placed on carbon sticky tabs mounted on aluminium SEM stubs. Once mounted samples were dried under vacuum in a desiccator for 48 hours. These dried samples were then gold coated for two minutes at $12 \mu \mathrm{A}$ using a sputter coater.

\section{Transmission electron microscopy}

A small sample of the gel was placed onto the TEM sample support grid (holey-carbon) using a spatula, then placed into the TEM. A Philips CM30 instrument, operating at a voltage of $300 \mathrm{kV}$, was used. Images and diffraction patterns were collected on photographic film, which was subsequently scanned to produce digital images. Electron diffraction patterns were indexed by 
comparison with numerous known and predicted crystal structures: the positions of reflections in experimental diffraction patterns were measured, converted to $d$-spacings and, along with interplanar angles, matched to calculated values for these predicted structures. The experimental diffraction patterns were then compared with simulated diffraction patterns of the appropriate zone axes, to ensure a match.

\section{NMR spectroscopy}

\section{a. Solution-state NMR}

i. ${ }^{1} \mathrm{H}$ NMR peak intensity measurements and determination of the soluble components of phenylalanine hydrogel

Series of ${ }^{1} \mathrm{H}$ solution-state NMR experiments were performed using a Bruker Avance I 499.69 MHz spectrometer equipped with a triple resonance probe. The concentration of phenylalanine in solution varied from 17.1 to $302.7 \mathrm{mM}$. In each quantitative experiment 16 scans were acquired with a pre-scan delay of $16 \mathrm{~s}$, to enable full relaxation of Phe and residual water. The receiver gain was set at the Phe concentration of $211.9 \mathrm{mM}$ and kept constant throughout the series of the experiments. The length of the ${ }^{1} \mathrm{H} \pi / 2$ pulse was calibrated for each concentration. The integration of the peaks was performed with Bruker Topspin software. The data presented in Figure 3 show average integrated intensities of all Phe protons with standard deviations.

\section{ii. ${ }^{1} \mathrm{H}$ NMR chemical shifts measurements}

In order to investigate local environment of Phe molecules during the aggregation process, changes in ${ }^{1} \mathrm{H}$ chemical shifts were measured. A series of solutions of Phe with different concentrations were investigated using ${ }^{1} \mathrm{H}$ NMR with a range from $1.2-194.6 \mathrm{mM}$. All chemical shift measurements were performed using DSS (4,4-dimethyl-4-silapentane-1-sulfonic acid) as an internal standard. 
iii. ${ }^{1} \mathrm{H}$ spin-lattice relaxation times

${ }^{1} \mathrm{H}$ spin lattice relaxation times $\left(\mathrm{T}_{1}\right)$ were measured using the inversion-recovery method at 25 ${ }^{\circ} \mathrm{C} .16$ increments were acquired with a maximum time delay of $60 \mathrm{~s}$. The obtained data were fit with Bruker Dynamics Centre software.

\section{b. HR-MAS NMR}

HR-MAS NMR spectra were acquired using a Bruker Avance III solid-state NMR spectrometer operating at $400.23 \mathrm{MHz}$ for ${ }^{1} \mathrm{H}$ and $100.64 \mathrm{MHz}$ for ${ }^{13} \mathrm{C}$, and the instrument was equipped with a double resonance HR-MAS probe. Gels were prepared immediately before the experiment inside the plastic MAS inserts and tightly sealed to avoid any spillage during sample spinning. Spinning speeds were optimised to avoid phase separation of the gels due to centrifugal forces. All gels were found to be undamaged after experiments.

\section{c. Solid-state NMR}

All solid-state NMR spectra were acquired using a Bruker Avance III solid-state NMR spectrometer operating at $400.23 \mathrm{MHz}$ for ${ }^{1} \mathrm{H}$ and $100.64 \mathrm{MHz}$ for ${ }^{13} \mathrm{C} .{ }^{1} \mathrm{H}-{ }^{13} \mathrm{C}$ crosspolarisation/magic angle spinning experiments (CP/MAS) were acquired using the RAMP CP pulse sequence. The ${ }^{1} \mathrm{H} \pi / 2$ pulse length was optimised to $3.20 \mu \mathrm{s}$, along with optimisation of the pulse delay to $10.0 \mathrm{~s}$. SPINAL64 decoupling was used and the contact time (for CP) was set to 2.0 ms. Hartmann-Hahn conditions were set with HMB (hexamethylbenze). TMS (tetramethylsilane) was used as a reference.

\section{NMR chemical shift calculations based on First Principles Density Functional Theory (DFT) calculations with CASTEP}

Computations were performed using the CASTEP code. ${ }^{30}$ Due to the known issues with the Xray diffraction determination of the positions of hydrogen atoms from the crystallographic data, 
the optimisation of the elucidated crystal structure is required. Geometry optimisations were carried out using the PBE exchange-correlation functional, ${ }^{31}$ a plane wave basis set cut-off energy of $1100 \mathrm{eV}$ and ultrasoft pseudopotentials ${ }^{32}$. These parameters were optimised for convergence. Geometry optimisation was run with constrained cell dimensions, allowing all the atoms to relax freely, and with constraining both cell dimensions and positions of all heavy atoms. In the optimised structure, average forces acting on each species were lower than $0.0001 \mathrm{eV} / \AA$.

The NMR chemical shieldings were calculated using the gauge including projector augmented wave approach (GIPAW) ${ }^{33}$ and the same parameters as for geometry optimisation. We performed calculations on the following structures: i) Phe monohydrate structure previously reported by Harris and co-workers ${ }^{11}$ without geometry optimisation, ii) optimised structure with only constrained cell dimensions and iii) optimised structure with constrained cell parameters and position of all heavy atoms. The isotropic NMR shieldings computed with CASTEP were converted to chemical shifts using the following equation:

$\delta_{\text {calc }}=\sigma_{\text {iso }}-\sigma_{\text {ref }}$,

where $\sigma_{\text {iso }}$ is the isotropic chemical shielding generated from first-principles calculations and $\sigma_{\text {ref }}$ was chosen as the zero intercepts of the fits of the calculated shielding vs. experimental chemical shift plot.

\section{Crystal structure prediction}

Crystal structures of Phe were predicted using a global lattice energy exploration approach, with the aim of finding all low energy crystal packings of the molecule within the space group symmetries considered in the study. The overall strategy for predicting the crystal structures of flexible molecules has been fully described elsewhere ${ }^{34}$ and has been shown to work well on a set 
of single-component ${ }^{35}$ and two-component ${ }^{36}$ amino acid crystal structures. The steps involved in the calculation are:

d. a conformational analysis of phenylalanine and selection of molecular geometries to build trial crystal structures;

e. generation of crystal structures for each molecular conformation and for each combination of molecular conformations for $Z^{\prime}=2$ searches;

f. lattice energy minimisation of the trial crystal structures, allowing the molecular geometry to adjust to the packing forces within each crystal structure;

g. a final energy evaluation to include the effects of polarisation on the lattice energies;

h. ranking the structures in order of increasing total (inter + intramolecular) energy.

Six stable conformations were identified and included in the crystal structure prediction study (Fig. S4.1).

Crystal structures were generated using a Monte Carlo simulated annealing approach ${ }^{37}$, as implemented in the Polymorph module of the Materials Studio package ${ }^{38}$, followed by rigid molecule lattice energy minimisation of each trial crystal structure. Crystal structures were generated in the 5 most commonly observed chiral space groups for organic molecular crystals $\left(P 1, P 2_{1}, P 22_{2} 2_{1}{ }_{1}, P 22_{1}{ }_{1} 2\right.$ and $\left.C 2\right)$, each with one $\left(Z^{\prime}=1\right)$ and two $\left(Z^{\prime}=2\right)$ molecules per asymmetric unit. Individual searches were performed with each of the six conformations and $21 Z^{\prime}=2$ combinations of molecular conformations. Up to 5 independent simulated annealing runs were performed for each $Z^{\prime}=1$ space group / conformer combination, and between 8 and 32 independent simulations in each $Z^{\prime}=2$ space group / conformer combination, until no new low energy crystal 
structures were located. The energy minimisations performed during this initial stage of the calculations employed the COMPASS force field with an atomic point change model for electrostatics, with charges fitted to the B3LYP/DNP molecular electrostatic potential, calculated using DMol3.

All structures within $25 \mathrm{~kJ} \mathrm{~mol}^{-1}$ of the global minimum for each conformer were then reoptimised, allowing for molecular flexibility, using the CrystalOptimizer software, allowing all dihedrals around exocyclic single bonds and angles around the $\mathrm{NH}_{3}$ group to relax under the influence of crystal packing forces. N-H bond lengths were constrained to $1.035 \AA$. Intermolecular interactions in these re-optimisations were described by an exp-6 repulsion-dispersion model with parameters for $(\mathrm{N}) \mathrm{H}$ hydrogen atoms were taken from Coombes et al. ${ }^{39}$ and from Williams ${ }^{40,41}$ for other atom types, as in our previous amino acid studies. ${ }^{35,36}$ Electrostatic interactions were modelled by a distributed multipole analysis ${ }^{42}$ of calculated B3LYP/6-31G** charge densities, with multipoles up to hexadecapole on each atom.

\section{RESULTS AND DISCUSSION}

\section{Macroscopic properties of Phe gels in water and DMSO}

We studied gelation by Phe in two solvents, water and dimethyl sulfoxide (DMSO). In the cases of both water and DMSO, pure solvents are required; mixing water and DMSO does not lead to gelation. In all cases studied, the chirally pure versions of Phe were required for gelation to occur. Racemic mixtures and a slight enantiomeric excess resulted in crystallisation in all solvents and no observation of gelation, as recently noted by Thakur. ${ }^{4}$ The minimum critical gel concentrations (CGCs) are shown in Table 1. In all solvents, above a certain concentration, the processes of gelation occur simultaneously with crystallisation of the anhydrous form I, and can be fully retarded if crystallisation dominates. We take this point to be where only pure gelation occurs with 
no obvious presence of anhydrous crystallisation, and is represented in Table 1 as the maximum concentration. In water, the gelation is dependent on ionic strength of the solution and its $\mathrm{pH}$, as described by Thakur and co-workers (Table S1 and Figure S2). ${ }^{4}$ As highlighted by Popov and coworkers on a different compound, $\mathrm{pH}$ and ionic strength of the water utilised in the gelation of the zwitterionic compound, like Phe, can result in changing behaviour. ${ }^{43}$ We noted that the gels were rheologically weaker upon changing the $\mathrm{pH}$ away from its $\mathrm{pI}$ value and addition of salt $(\mathrm{NaCl})$ (Table S2.1). The gels became metastable upon addition of $\mathrm{NaCl}(>100 \mathrm{mg}$ per $5 \mathrm{ml})$, preferring the formation of the crystalline anhydrous Form 1. This observation is consistent with results published by others concerning the crystallisation of Phe ${ }^{8,9}$ We were able to follow the crystal-tocrystal conversion from the gel (monohydrate) phase to the crystalline Form 1 of the concentrated brine solution utilising rheology (following the decrease in $G^{\prime}$ ) (Figure S2). The rheology of the gels (both in DMSO and water) provides clear cut evidence of the viscoelastic nature of the materials and the importance of defining these phases as gels. Frequency sweep rheometry with a small amplitude stress of the materials revealed the solid-like nature of the gels at $20{ }^{\circ} \mathrm{C}$ with the storage modulus, $G^{\prime}$, being typically an order of magnitude greater than the loss modulus, $G^{\prime \prime}$. The non-linear rheological response for the gels was also investigated using stress sweep experiments, during which an oscillatory torque was imposed with a fixed frequency over a range of shear stress amplitudes. The gels showed a typical $G^{\prime}$ value, essentially constant below the critical value of oscillatory torque ("yield stress"), again showing behaviour typical of a gelatinous material. (Figures S2.1-2.6). The high elastic moduli values for the hydrogels reveal a robust material. For a wide range of cellular solid materials across a range of cellular concentrations, the formula $\mathrm{G}^{\prime} \approx$ $3 \mathrm{E}_{\mathrm{s}}\left(c / \rho_{\mathrm{s}}\right)^{2} / 8$ holds true, where $\mathrm{E}_{\mathrm{s}}$ is the Young's modulus of the struts, and $c$ is the concentration of the compound making up those struts. For the hydrogel, the $\mathrm{E}_{\mathrm{s}}$ value is determined to be 1.7 
$\mathrm{GPa}(+/-0.2)$, which is comparable to that calculated for other LMWGs, semi-crystalline polymers and organic crystal materials such as amino acids. ${ }^{44,45}$ The cellular solid model describes an opencell cellular material which consists of load bearing struts (fibres) interconnected via cross-links or junction points which deform by bending. The fibrous nature of the material was confirmed through imaging by electron microscopy of the water gels (Figure S.1). The DMSO gels are not stable in the absence of the solvent, resulting in crystallisation of form I upon drying, according to Görbitz nomenclature of the phase diagram. ${ }^{9}$ This makes standard imaging of the gel morphology difficult. Even when drying appears to give fibres, these fibrous crystals are of form I (Figure S3.2).

Table 1. Gelation parameters for Phe

\begin{tabular}{|l|l|l|l|}
\hline Solvent & Min. CGC $[\mathrm{mM}]$ & Max. Conc. $[\mathrm{mM}]$ & Appearance \\
\hline Water & 212 & 605 & $\begin{array}{l}\text { Opaque and } \\
\text { Crystalline }\end{array}$ \\
\hline DMSO & 50 & 240 & Transparent \\
\hline
\end{tabular}

\section{"Gel-crystallisation": morphology}

As mentioned above, the phenomenon of Phe gelation in water had previously been described as "gel-crystallisation". To test why this may be the case we performed diffraction studies on the gel samples. This revealed that the dry and wet hydrogels are considerably crystalline in nature, with no indications of amorphous or semi-crystalline phases (Figures S1.1). The TEM diffraction images of dried samples, Figure 1, also revealed a single phase of excellent crystallinity. Initial attempts to identify this phase were unsuccessful until the PXRD data produced by Harris and coworkers confirmed the material to be the hydrate phase of Phe. ${ }^{11}$ We were able to confirm this phase by obtaining single crystal data sets of both the monohydrate and hemihydrate forms of Phe 
from fibres pulled directly from the gels. We believe that the process of isolating the fibre from the gelation mixture can result in dehydration of the hydrate phase to give a crystal of the hemihydrate form, as reported by Harris et al. ${ }^{11}$ Solid-state NMR studies performed directly on the hydrogel phase are in agreement with spectra presented by Harris and co-workers for Phe monohydrate ${ }^{11}$ and further assigned this material as the monohydrate crystal form utilising chemical shift calculations with CASTEP (see experimental section and S.I. for NMR data and analysis). Further discussion on the use of NMR to understand this phase, and its relationship with the hydrogel phases, is given later is this paper. In strong contrast to the hydrogel materials, the gels of DMSO appear to be non-crystalline when X-ray diffraction is utilised on the solvate phases.

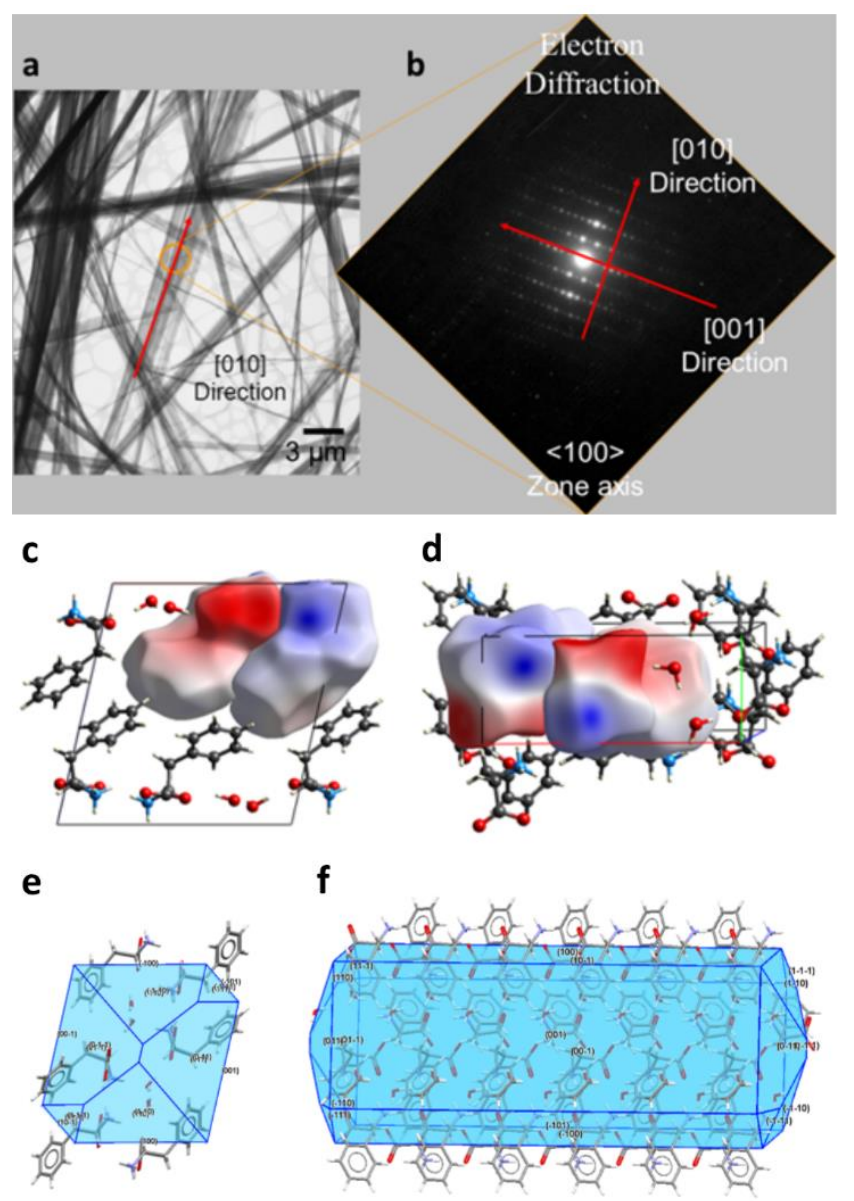


Figure 1. The determination of the hydrate structure of the hydrogel allows for a) the morphology of the fibres by TEM to be confirmed and $b$ ) the molecular packing in these fibres determined by electron diffraction. Zone axis electron diffraction of the fibres indicates the growing direction to be the [010] crystallographic direction. Analysis of the crystal structure indicates that $c$ ) the electrostatics (shown here as the electrostatic potential Hirshfeld surface) is a significant interaction for the stacking of Phe in this anisotropic manner, with $\pi-\pi$, hydrogen bonding and van der Waals interactions complementing the $+/-/+-$ stacking in the [010] direction. c) Shows the structure viewed down [010] and d) is shown viewed down the [001] with b axis colored green, a axis red and $\mathrm{c}$ axis blue. e, f) BFDH crystal morphology calculation indicates a needle habit of Phe monohydrate.

With the molecular packing of Phe in this hydrogel form at hand, we could analyse the morphological characteristics of the self-assembly, i.e., why Phe is forming fibrous assemblies. The BFDH crystal morphology calculation, which only takes into account crystallographic geometrical considerations (unit cell and symmetry operator information) indicates a needle habit (Figures 1, S1.5 and S1.6). The other three polymorphs show rhombus like BFDH habits, which match that of the experimental habits, except for form IV, which was found as a needle form. ${ }^{8,9}$ The non-growing faces of the morphology are the (100) and (001), and clearly represent hydrophobic faces (Fig. 1 e, f). This, however, does not fully explain the "extreme" needle/fibre morphology. Intermolecular, supramolecular interaction analyses of the crystal structure also do not divulge any clear "uni-directional" interactions such as hydrogen bonding, $\pi$ - $\pi$ stacking or van der Waals interactions. The influence of electrostatics in the form of Coulombic interactions is sometimes underestimated, even though they can make a dominant contribution to intermolecular interactions, and their strong directionality often makes them structure-determining. ${ }^{46-49}$ The 
electrostatic potential Hirshfeld surface analysis of the symmetry unique Phe molecules of the monohydrate structure shows the anisotropy of the molecules (Figures 1 and S1.7-1.12). This clearly shows that Coulombic interactions are an important intermolecular force in determining the fibre morphology. This is confirmed by face indexing the fibres by electron diffraction in TEM experiments. The electron diffraction patterns obtained are a match for the calculated patterns from the monohydrate crystal structure. The direction of the long axis of the fibres can be attributed to the [010] direction of the monohydrate structure. The [010] direction corresponds to the stacking of the positive and negative charges of the zwitterionic Phe molecules in an expected $+/-/+/-$ etc. arrangement.

\section{Computational modelling of structure of Phe gels}

As the solid matrix of the hydrogel is clearly crystalline in nature, we utilised crystal structure prediction (CSP) calculations to investigate the structural landscape of Phe. CSP is approached as a global lattice energy minimisation problem, seeking to locate and assess the relative stabilities of all possible ways of packing molecules into ordered crystal structures, taking no account of the required kinetic pathways to these structures. This is a powerful approach for exploring the solidstate structural landscape of molecules and can give insight into possible polymorphism, as well as hydrate formation and gelation. ${ }^{22-26,50,51}$ CSP calculations were performed in the common Sohncke space groups with $Z^{\prime}=1$ and 2 , also taking into account the conformational flexibility of the molecule. The methodology used in the CSP study employs a hybrid energy model, using DFT intramolecular energetics combined with an atomic multipole based atom-atom force field for

intermolecular interaction. The approach was based on our previous CSP studies of single ${ }^{35,52}$ and two-component ${ }^{36}$ amino acid crystal structures, and full details are provided in the methods section 
and S.I.. Lattice energy calculations were also performed on the known $Z^{\prime}=4$ forms I and III for comparison of their stabilities to the $Z^{\prime}=1$ and $Z^{\prime}=2$ landscape of structures.

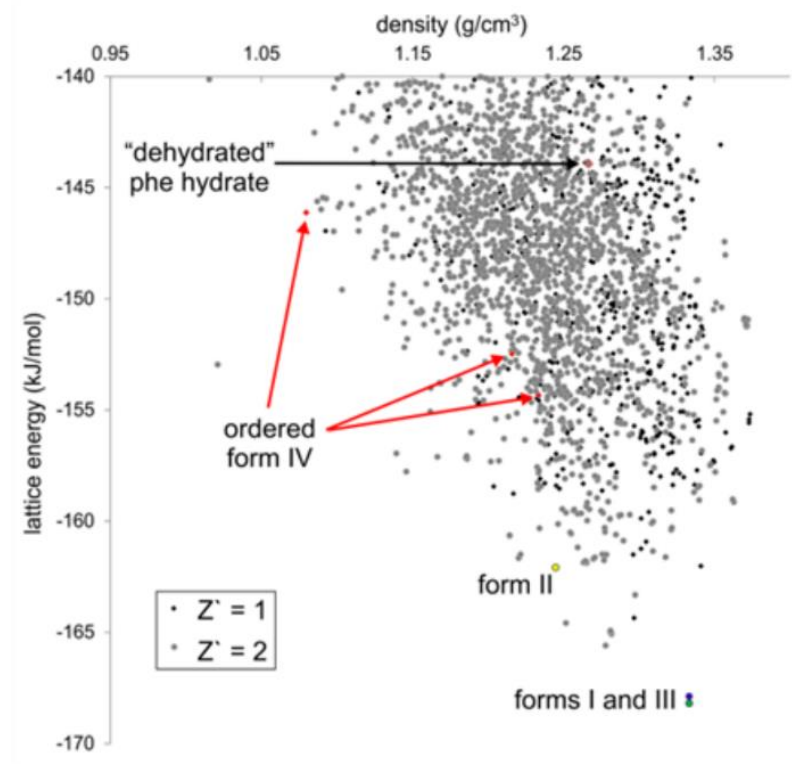

Figure 2. Calculated energy landscape of $L$-phenylalanine. $Z^{\prime}=1$ and $Z^{\prime}=2$ predicted crystal structures are indicated as grey circles and black diamonds. The known forms I, II and III, as well as a number of ordered versions of form IV are indicated. Also highlighted is the structure resulting from in silico dehydration of the monohydrate form found in the hydrogel.

The results, summarised in Figure 2, demonstrate a very rich structural landscape, from which we can make several conclusions. Firstly, we find that the known $Z^{\prime}=4$ polymorphs are more stable than any of the predicted structures, $2.6 \mathrm{~kJ} \mathrm{~mol}^{-1}$ below the most stable $\mathrm{Z}^{\prime}=2$ predicted structure; the low symmetry packing in these polymorphs seems to be driven by a lowering of the lattice energy, which cannot be achieved within the constraints of smaller $\left(Z^{\prime}=1\right.$ and $\left.Z^{\prime}=2\right)$ asymmetric units. However, we also noticed that forms I and III lattice energy minimise to the same structure. These structurally very similar assemblies do not correspond to different energy minima on the energy surface described by the methods used here. 
Amongst the predicted structures, we find several low energy $Z^{\prime}=1$ structures and a large number of possibilities with $Z^{\prime}=2$, with a slight energetic preference for $Z^{\prime}=2$. The known form II is located as one of the lowest energy predicted structures (Figure 4), $3.5 \mathrm{~kJ} \mathrm{~mol}^{-1}$ above the lowest energy prediction, and $6 \mathrm{~kJ} \mathrm{~mol}^{-1}$ above forms I and III. To compare the conformationally disordered form IV with the predicted structures, we lattice energy minimised three ordered versions of form IV, each with one of the side chain conformations seen in the observed structure. The resulting lattice energy minima correspond to structures that were found in our $Z^{\prime}=1$ prediction results and are highlighted in Figure 2. These ordered structures are all at lower density than the observed disordered structure, and also outside of the normal energetic range of polymorphism, demonstrating the importance of the disorder in the close packing and stability of form IV.

The calculated lattice energy $\left(-252.0 \mathrm{~kJ} \mathrm{~mol}^{-1}\right)$ of the hydrate is $83.8 \mathrm{~kJ} \mathrm{~mol}^{-1}$ lower than that of forms I and III. This stabilisation provided to the lattice by water is approximately double water's vaporisation enthalpy, so greatly exceeds the cost of removing water from its pure phase. This suggests that the hydrate is the thermodynamically stable form in the presence of water. For comparison, we removed the water and re-optimised the structure. The resulting computationally "dehydrated" structure corresponds to one of the high energy predicted $Z '=1$ structures (shown in Figure 2). The results show that the stability of the hydrate is dominated by the hydrogen bond interactions involving the lattice water. This is reflected in the contributions to the lattice energy: the lattice energy of the hydrate is more than $93 \%$ electrostatic, compared to $73 \%$ (forms I and III) and $74 \%$ (form II) in the known anhydrous polymorphs. These observations complement the unidirectional growth analyses described earlier in this paper.

\section{Monitoring self-assembly of Phe in water and DMSO using NMR methods}


The processes of gelation and crystallisation have the common starting point in solution of selfassembly/aggregation, nucleation and growth (although it must be noted that some small molecule gelators can show isodesmic supramolecular polymerisation). To study self-assembly processes within both systems we turned to NMR as it is sensitive to the local environment of the interacting species and conformational changes, which can be observed as changes in the chemical shifts. Phe spectra in $\mathrm{D}_{2} \mathrm{O}$ show six distinct sites labelled in Figure 3A. These include three sites of aromatic region (two $\mathrm{H}_{\mathrm{a}}$ equivalent protons, two $\mathrm{H}_{\mathrm{c}}$ equivalent protons, $\mathrm{H}_{\mathrm{b}}$ proton), aliphatic proton $\mathrm{H}_{\mathrm{f}}$ in the chirality centre at $c a .3 .9 \mathrm{ppm}$ and peaks from two protons $\mathrm{H}_{\mathrm{d}}$ and $\mathrm{H}_{\mathrm{e}}$ grouped at 3.18 and 3.01 $\mathrm{ppm}$. The high intensity peak at $4.7 \mathrm{ppm}$ is due to the residual water and exchangeable protons.

In comparison, the ${ }^{1} \mathrm{H}$ spectrum of phenylalanine in DMSO-d6 shows significant differences indicating that solvent has a considerable effect on the local environment of hydrogen atoms, which may be related to solvent induced conformational changes. The differences between ${ }^{1} \mathrm{H}$ Phe spectra in $\mathrm{D}_{2} \mathrm{O}$ and DMSO-d6 can be seen in the aromatic region of the spectrum displaying an upfield shift of the $\mathrm{H}_{\mathrm{b}}$ proton and a downfield shift of the $\mathrm{H}_{\mathrm{c}}$ protons. The aliphatic region of the spectrum displays significant differences in chemical shifts of protons $\mathrm{H}_{\mathrm{d}}$ and $\mathrm{H}_{\mathrm{e}}$ (at 3.16 and 2.84 ppm) alongside substantial upfield shift of the $\mathrm{H}_{\mathrm{f}}$ proton (from $3.9 \mathrm{ppm}$ in $\mathrm{D}_{2} \mathrm{O}$ to $3.3 \mathrm{ppm}$ in DMSO-d6). As a result, this line overlaps with the exchangeable protons peak at $c a .3 .3 \mathrm{ppm}$ (compare grey and black spectra in Figure $3 \mathrm{~B}$ ). Vicinal coupling constants $3 \mathrm{~J}_{\mathrm{ef}}$ and $3 \mathrm{~J}_{\mathrm{df}}$ are similar in both solvents (DMSO-d6 3J $\mathrm{J}_{\mathrm{ef}}=8.55 \mathrm{~Hz}$ and $3 \mathrm{~J}_{\mathrm{df}}=3.92 \mathrm{~Hz}, \mathrm{D}_{2} \mathrm{O} 3 \mathrm{~J}_{\mathrm{ef}}=8.11 \mathrm{~Hz}$ and $3 \mathrm{~J}_{\mathrm{df}}=5.25$ $\mathrm{Hz}$ ) indicating only small differences in geometry of the phenylalanine aliphatic motif. The solution ${ }^{1} \mathrm{H}$ NMR spectra of the Phe gels in $\mathrm{D}_{2} \mathrm{O}$ and DMSO show substantial broadening of the peaks, which is related to short $\mathrm{T}_{2}$ relaxation times together with increased ${ }^{1} \mathrm{H}-{ }^{1} \mathrm{H}$ dipolar interactions within aggregating solid-like structures. 

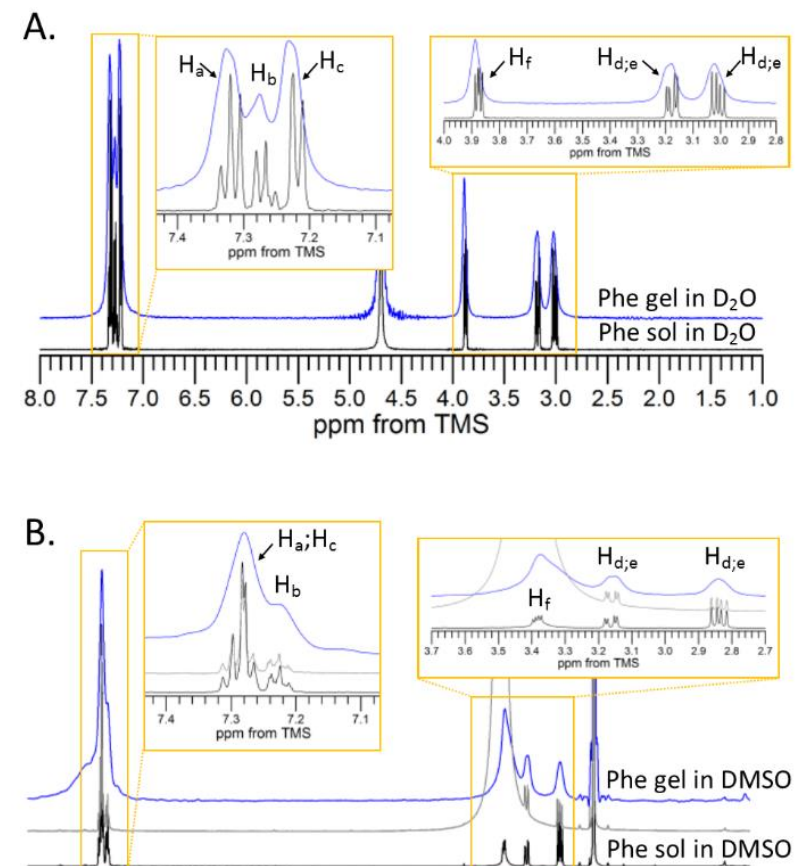

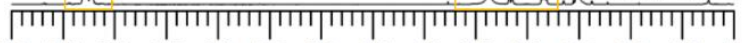

$\begin{array}{lllllllllllllllllll}8.0 & 7.5 & 7.0 & 6.5 & 6.0 & 5.5 & 5.0 & 4.5 & 4.0 & 3.5 & 3.0 & 2.5 & 2.0 & 1.5 & 1.0\end{array}$ ppm from TMS

Figure 2. ${ }^{1} \mathrm{H}$ NMR spectra of Phe solution and gel in A. $\mathrm{D}_{2} \mathrm{O}$ and B. DMSO-d6. The exchangeable protons peak (bottom [black] spectrum in B.) was suppressed using pre-saturation pulses to show an overlap with $\mathrm{H}_{\mathrm{f}}$ protons of Phe in DMSO-d6.

It has been shown using vibrational spectroscopy that electrostatic interactions between $-\mathrm{NH}_{3}{ }^{+}{ }^{-}$OOC- motifs are key in the Phe self-assembly ${ }^{1,2,53}$, however recently, it has been hypothesised that there are significant contributions of hydrophobic interactions of the phenyl rings in the formation of Phe fibrils. ${ }^{4,8}$ We are interested in ascertaining the main driving force of the fibre formation, which from the crystallographic characterisation appears to be the electrostatic interactions. In order to gain better understanding of the Phe self-assembly in water and DMSO we have studied Phe aggregation processes over a wide range of concentrations mediated by changes in ${ }^{1} \mathrm{H}$ chemical shifts (Figure 3 ). 


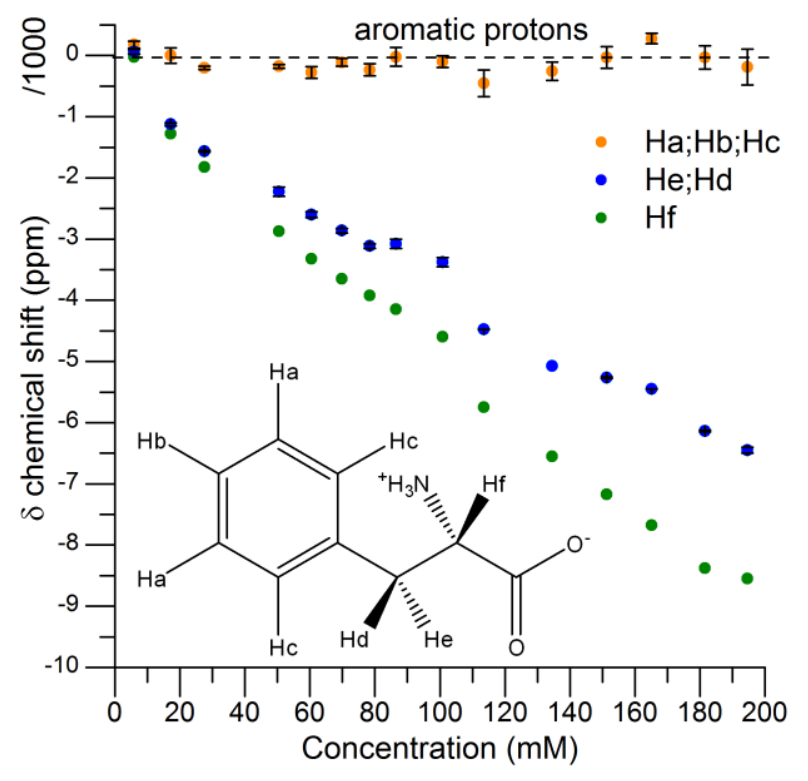

Figure 3. Changes of Phe ${ }^{1} \mathrm{H}$ NMR chemical shifts with increasing concentration in $\mathrm{D}_{2} \mathrm{O}$. Aliphatic ${ }^{1} \mathrm{H}$ shifts clearly indicate the aggregation process to be facilitated through the interactions of the zwitterionic end of the molecules and not the aromatic regions $\left({ }^{1} \mathrm{H}\right.$ sites on the aromatics do not shift with aggregation).

It is clear that the local environment of the aromatic region of the aggregating species is practically unchanged during the increased saturation induced self-assembly. Furthermore, substantial changes in the chemical shifts of aliphatic protons $\mathrm{Hd}, \mathrm{He}$, Hf prove unambiguously the importance of the aliphatic region in Phe self-assembly. This is corroborated by the structural studies of the Phe monohydrate, building block of the gel fibrils, where short contact interactions between aromatic rings of Phe are negligible. ${ }^{11}$ 

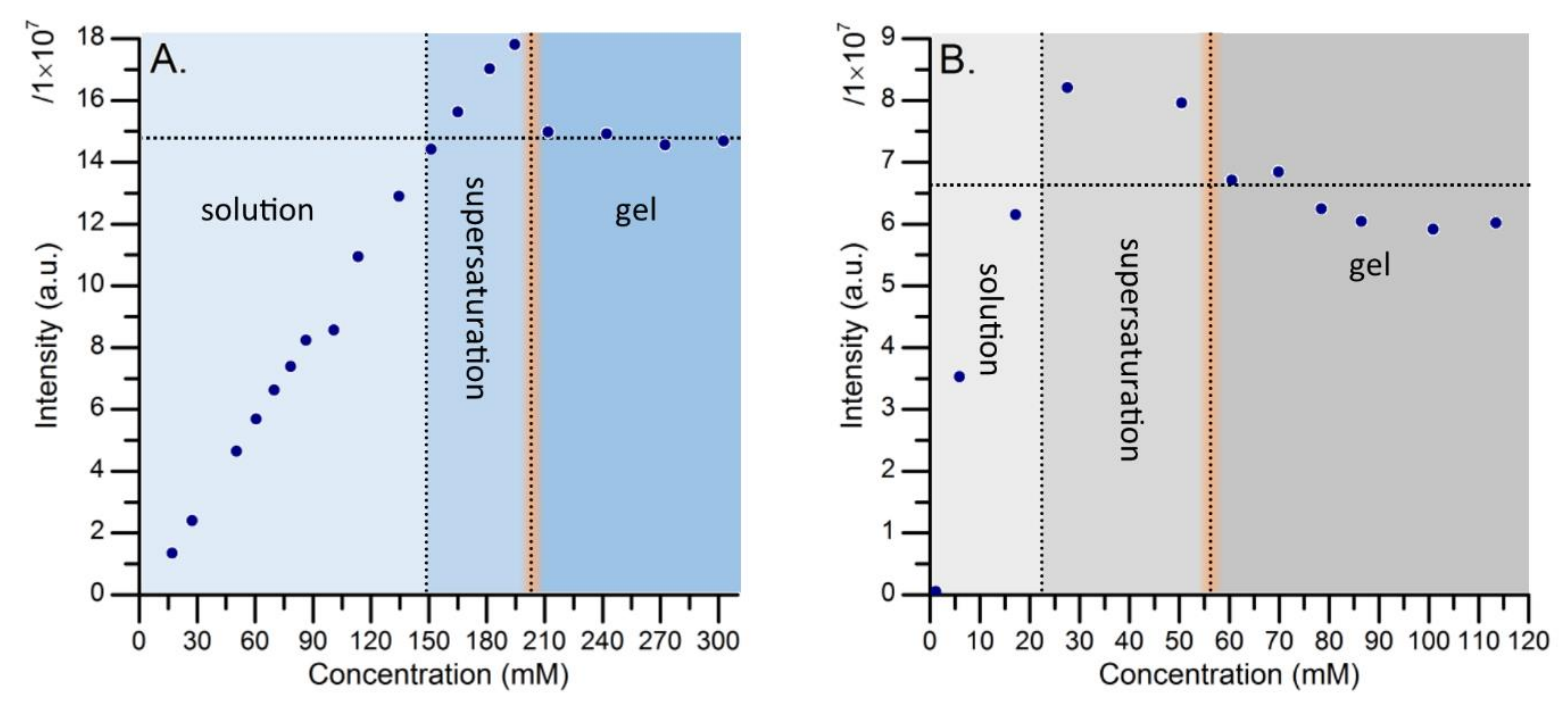

Figure 4. Dependence of ${ }^{1} \mathrm{H}$ NMR peak intensity on the concentration of Phe in $\mathrm{A} . \mathrm{D}_{2} \mathrm{O}$ and $\mathrm{B}$. DMSO-d6. Three different stages during the gelation process can be identified based on intensities of the peaks, i.e. solution, supersaturated solution and gel phase. In the gel phase there is no increase in intensities despite increasing concentration. Orange line indicates NMR determined CGC.

In ${ }^{1} \mathrm{H}$ solution NMR only dissolved gelator molecules are 'visible' and molecules bound in the rigid network stay silent due to short $\mathrm{T}_{2}$ relaxation times, strong dipolar couplings and chemical shift anisotropy. ${ }^{54} \mathrm{As}{ }^{1} \mathrm{H}$ NMR is a quantitative analytical method, we were able to determine the critical gelation concentration and the ratio between Phe species dissolved in the aqueous phase of the gel and Phe bound in a rigid gel network. A linear increase of the intensity of NMR peaks is observed in the range of Phe concentrations from 17 to $200 \mathrm{mM}$ (Figure 4a). When the concentration of Phe reaches the critical gelation concentration (CGC) and a gel is formed, the saturation of the NMR peaks intensities is evident and no further increase of the intensity of NMR peaks can be observed with increasing solute concentration. As it is well known for LMWG that 
formation of supramolecular structure does not require all molecules to be incorporated in the gel network, certain concentration needs to be reached to drive spontaneous process of fibril formation. ${ }^{21,54}$ Based on that, the NMR-based CGC in water was determined at $c a .212 \mathrm{mM}$. We also note that Phe in the range of concentrations from $c a$. 160 to $200 \mathrm{mM}$ stayed in a supersaturated solution, which produced a gel in the NMR tubes at the air/water interface after 3 weeks of storage.

Table 2. Concentration of Phe in solution and in gel phase based on the ${ }^{1} \mathrm{H}$ NMR intensities.

\begin{tabular}{|c|c|c|}
\hline Phe concentration (mM) & Phe in gel phase $(\mathrm{mM})$ & Phe in solution $(\mathrm{mM})$ \\
\hline \multicolumn{3}{|l|}{ Phe gel in water } \\
\hline 211.9 & 51.7 & 160.2 \\
\hline 242.1 & 82.7 & 159.4 \\
\hline 272.4 & 116.8 & 155.6 \\
\hline 302.7 & 145.7 & 157.0 \\
\hline \multicolumn{3}{|l|}{ Phe gel in DMSO } \\
\hline 60.5 & 38.2 & 22.3 \\
\hline 69.8 & 47.0 & 22.8 \\
\hline 78.5 & \begin{tabular}{|l|l|}
57.7 \\
\end{tabular} & 20.8 \\
\hline 86.5 & 66.4 & 20.1 \\
\hline 100.9 & 81.2 & 19.7 \\
\hline 113.5 & \begin{tabular}{|l|l}
93.4 \\
\end{tabular} & 20.1 \\
\hline
\end{tabular}

The CGC of Phe in DMSO is $c a .4$ times smaller than the CGC of Phe in water, as determined with ${ }^{1} \mathrm{H}$ solution NMR (Figure 4 and 5, Table 2). A gradual increase of NMR peak intensity is observed up to the Phe concentration of $c a .20 \mathrm{mM}$. In the range of concentrations between 20 to $60 \mathrm{mM}$ it was possible to obtain Phe supersaturated solutions, which, if not agitated, formed a gel after a couple of hours. ${ }^{1} \mathrm{H}$ NMR analysis of the Phe DMSO gel phase in the concentration range 
from $60-110 \mathrm{mM}$ shows no significant changes in the NMR signal intensity. Similarly to the Phe gel in water, a further increase of the Phe concentration above the CGC does not affect the intensity of the NMR peaks due to the formation of solid fibrils, which are 'silent' in the solution-state NMR.
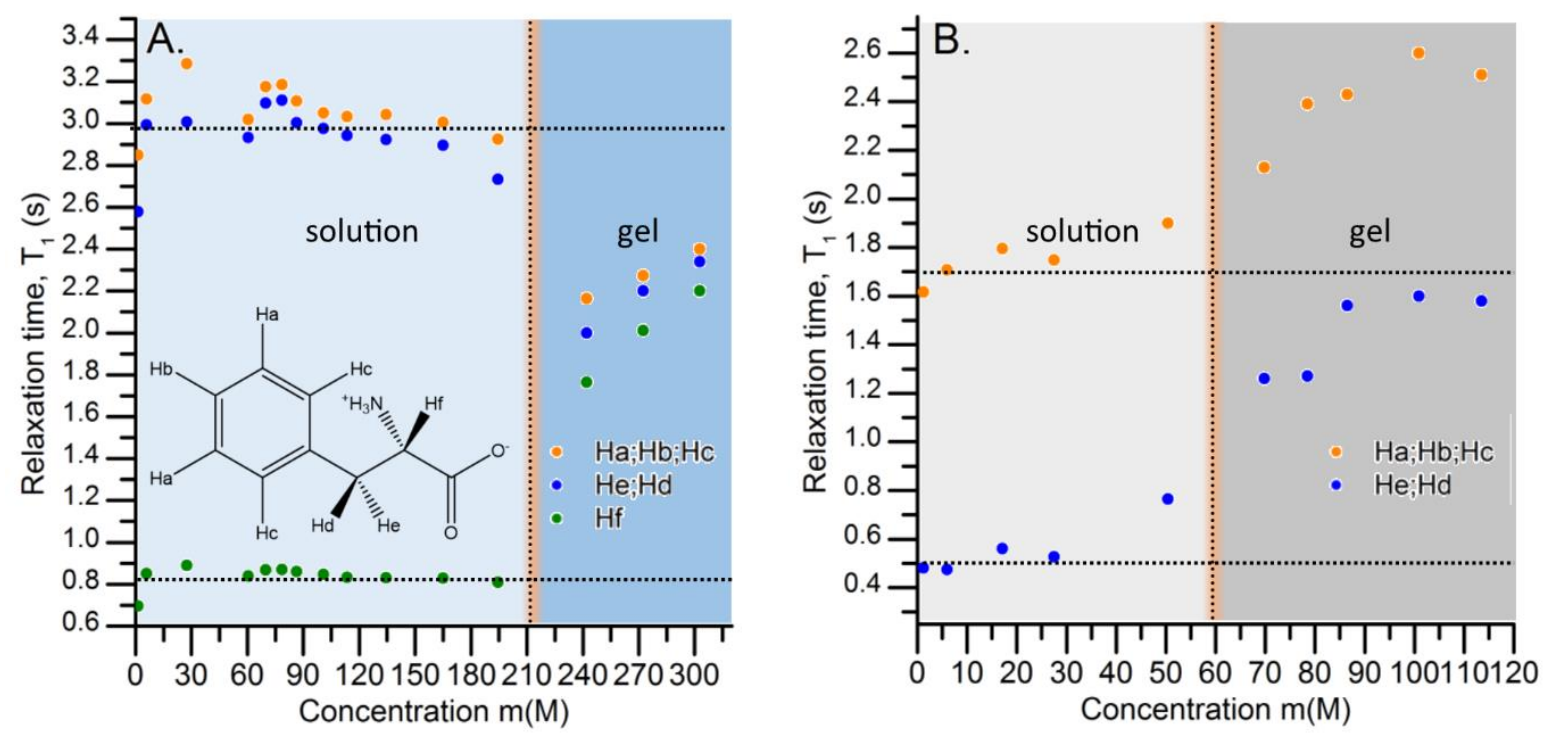

Figure 5. Evolution of ${ }^{1} \mathrm{H}^{\mathrm{T}} \mathrm{T}_{1}$ relaxation time of different regions of Phe as a function of concentration in A. $\mathrm{D}_{2} \mathrm{O}$ and B. DMSO-d6.

Dependence of ${ }^{1} \mathrm{H} \mathrm{T}_{1}$ relaxation times of Phe in water with increasing concentration provided a further insight towards the mechanism of fibre formation (Figure 5). Differences in local dynamics are observed between the protons of the aromatic group and $\mathrm{H}_{\mathrm{f}}$ protons, and the protons $\mathrm{H}_{\mathrm{d}}$ and $\mathrm{H}_{\mathrm{e}}$, prior to the gelation. There is a clear difference in the relaxation times for different ${ }^{1} \mathrm{H}$ sites in the solution before the formation of the gel. The long relaxation times $(c a .3 .0 \mathrm{~s})$ of the protons of the aromatic group and $\mathrm{H}_{\mathrm{f}}$ protons are contrasted by the three times shorter relaxation times of neighbouring $\mathrm{H}_{d}$ and $\mathrm{H}_{\mathrm{e}}$ protons. Upon formation of the gel, the values of the ${ }^{1} \mathrm{H} \mathrm{T}_{1}$ relaxation times for different ${ }^{1} \mathrm{H}$ sites become similar. This indicates an enhanced ${ }^{1} \mathrm{H}-{ }^{1} \mathrm{H}$ spin diffusion as a 
result of restricted mobility of the gelator. It is important to emphasise that ${ }^{1} \mathrm{H}$ solution NMR enabled us to observe molecules which are in the fast tumbling regimes on the NMR timescale, i.e. dissolved molecules in the solution entrapped in the gel network. Increases in the $\mathrm{T}_{1}$ relaxation time with increasing concentration of Phe in the gel state reflects possible aggregation of amino acid prior to growth of gel fibres, which is further confirmed by diffusion measurements (see S.I.).

The ${ }^{1} \mathrm{H}_{1}$ relaxation times dependence in the Phe water system is contrasted by Phe DMSO gel, where clear differences in the relaxation times between the protons of the aromatic group and aliphatic $\left(\mathrm{H}_{\mathrm{d}}\right.$ and $\left.\mathrm{H}_{\mathrm{e}}\right)$ protons are observed over a range of measured concentrations. Similarly to the Phe water system, the ${ }^{1} \mathrm{H} \mathrm{T}_{1}$ values of both ${ }^{1} \mathrm{H}$ sites of Phe in DMSO solution stay constant while a gradual increase in the ${ }^{1} \mathrm{H} \mathrm{T}_{1}$ in the gel state is observed, indicating formation of Phe aggregates.

\section{Understanding structural differences between Phe gels in water and DMSO}

${ }^{13} \mathrm{C}$ solid-state NMR spectra were recorded for both gels (in situ gel NMR with no desolvation) and the reference L-Phe commercial material (form I) without recrystallisation. Substantial differences can be seen in solid-state NMR spectra of both gels, as compared to the Phe form I. The Phe gel in water shows characteristic splitting for each carbon site indicating presence of two non-equivalent molecules in the crystal structure. It matches the spectra published by Williams et $a l$. for the high humidity material (Phe monohydrate phase). ${ }^{11}$ This is further corroborated by our PXRD results and CASTEP calculations of the solid-state NMR parameters for a geometry optimised Phe monohydrate crystal structure. 


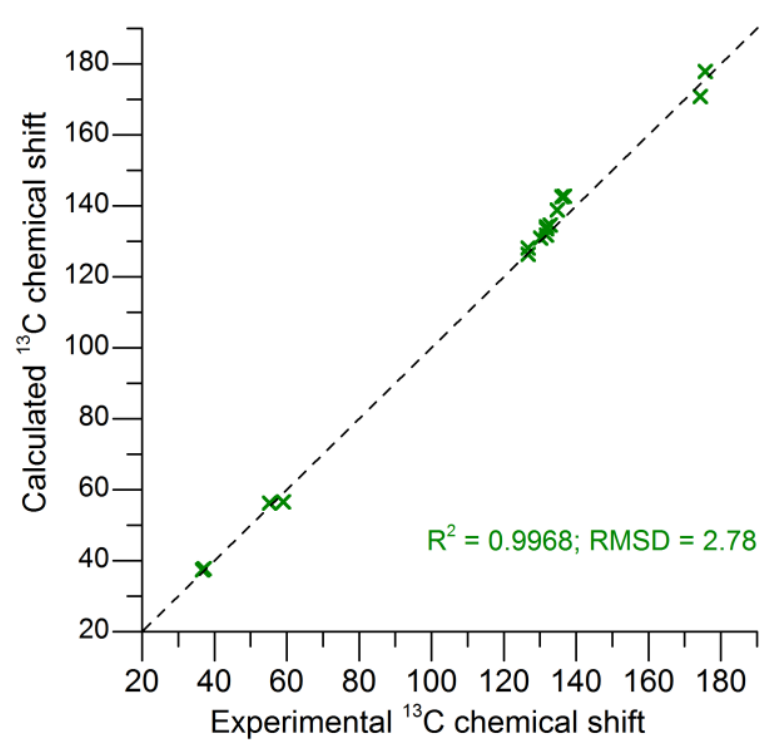

Figure 6. Experimental ${ }^{13} \mathrm{C}$ chemical shift values for Phe gel in water derived from the spectra acquired at an MAS rate of $10 \mathrm{kHz}$ vs. calculated chemical shifts for the Phe monohydrate that give best agreement with both NMR and PXRD from the gel. 

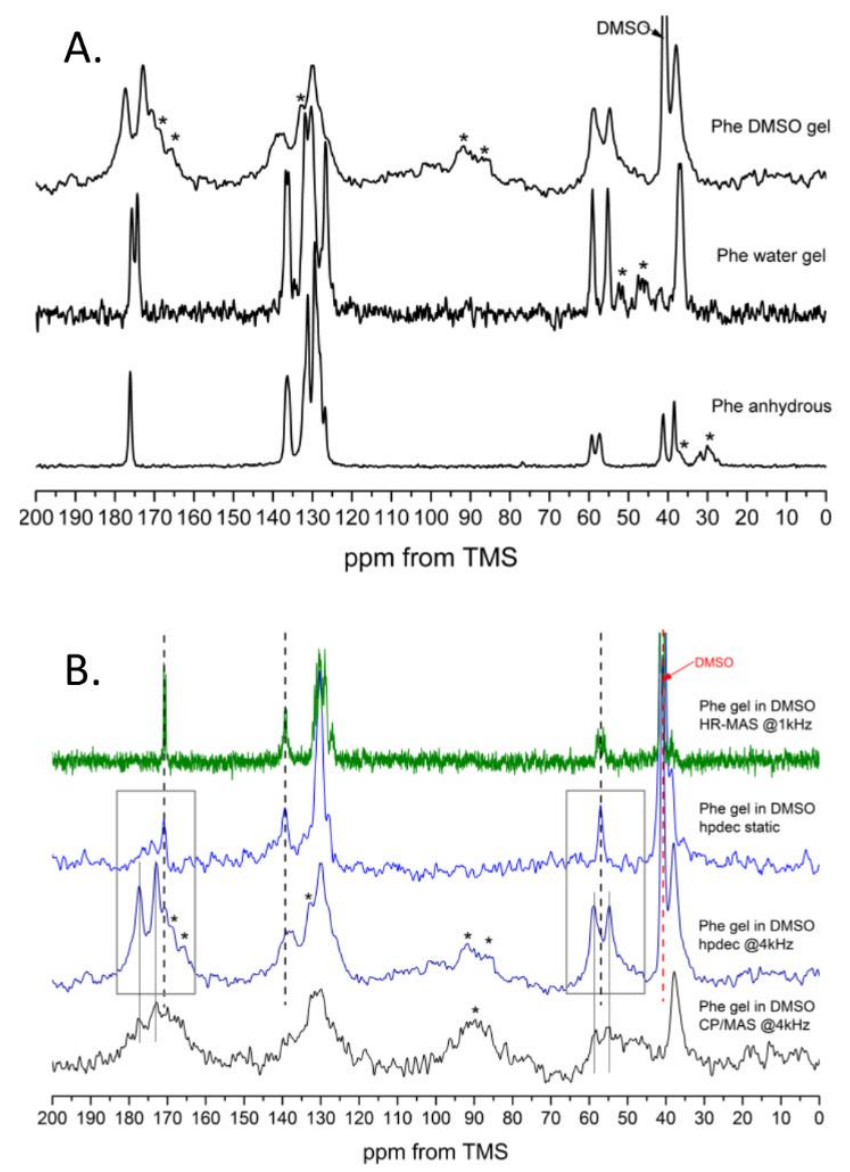

Figure 7. A. ${ }^{1} \mathrm{H}-{ }^{13} \mathrm{C} \mathrm{CP} / \mathrm{MAS}$ solid-state NMR spectra of anhydrous Phe and Phe water gel and ${ }^{13} \mathrm{C}\{\mathrm{H}\}$ solid-state NMR spectra of Phe in DMSO gel. The spectra for the Phe water gel matches exactly to that of the monohydrate crystalline phase which is a $Z^{\prime}=2$ structure. The spectra for the DMSO gel show broader peaks, indicating a less ordered phase which also exhibits two distinct chemical environments for the Phe molecules in the solid component of the gel. The spectra were recorded at different spinning speeds. Spinning sidebands are labelled with asterisks. B. Differences in mobile and rigid components of the Phe DMSO gel based on HR-MAS and solidstate NMR experiments (for experiments with or without spinning see S.I. for further details). 
The ${ }^{1} \mathrm{H}_{-}{ }^{13} \mathrm{C}$ CP/MAS NMR spectrum of Phe in the DMSO gel shows much broader peaks as compared to the Phe water gel, due to increased distribution of possible orientations of magnetically non-equivalent carbon atoms, which is consistent with low crystallinity of the material. The overall intensity of the ${ }^{1} \mathrm{H}-{ }^{13} \mathrm{C} \mathrm{CP} / \mathrm{MAS}$ NMR spectra is much lower compared to the spectra of the hydrogel, which may indicate ineffective cross-polarisation mechanism for Phe DMSO gel. The reduced efficiency of cross-polarisation is indicative of high mobility of solid component in DMSO gels and hence reduced strengths of ${ }^{1} \mathrm{H}-{ }^{13} \mathrm{C}$ dipolar couplings. As ${ }^{13} \mathrm{C}\left\{{ }^{1} \mathrm{H}\right\}$ MAS NMR does not rely on the strength of heteronuclear dipolar couplings it enabled simultaneous detection of both solid and liquid components of the gel. While in ${ }^{1} \mathrm{H}-{ }^{13} \mathrm{C} \mathrm{CP} / \mathrm{MAS}$ spectrum only aromatic and $-\mathrm{CH}_{2}$ motifs are observed, in the ${ }^{13} \mathrm{C}\left\{{ }^{1} \mathrm{H}\right\}$ MAS NMR spectrum all carbon sites of Phe can be distinguished. Interestingly, each ${ }^{13} \mathrm{C}$ peak is split into two separate peaks, indicating the gel fibres are composed of molecules in two distinct environments. This is clear for the carbonyl and $\mathrm{C} \alpha$ sites of the spectrum at $c a .175$ and $55 \mathrm{ppm}$ (Figure 7). As the ${ }^{13} \mathrm{C}\left\{{ }^{1} \mathrm{H}\right\}$ spectrum is composed of both the rigid and mobile components of the gel we performed additional experiments in order to distinguish between both species. Through the acquisition of ${ }^{13} \mathrm{C}\left\{{ }^{1} \mathrm{H}\right\}$ spectrum at static conditions (without spinning) we only detected isotropic, highly mobile Phe molecules in the DMSO gel, as the rigid component of the structure is largely broadened due to CSA (Chemical Shift Anisotropy) and dipolar interactions. Similarly, acquisition of the ${ }^{13} \mathrm{C} H R-$ MAS spectrum of Phe DMSO gel provides information only on the mobile component of the gel, complementing the ${ }^{13} \mathrm{C}\left\{{ }^{1} \mathrm{H}\right\}$ MAS NMR spectrum acquired at static conditions. In summary, using both solution and solid-state NMR methods we were able to distinguish between mobile and rigid components of Phe gels in water and in DMSO, which highlights the structural and dynamical differences between Phe gels in water and DMSO. The analysis of ${ }^{1} \mathrm{H}$ (and ${ }^{13} \mathrm{C}$ see ESI) solution- 
state NMR spectra showed significant differences between local environments of Phe molecules in different solvents which in turn lead to significant differences in the properties of obtained gels (e.g. strength of the gel, crystallinity, transparency).

\section{Conclusions}

In conclusion we have shown that Phe is a gelator in water and DMSO. The "gel-crystallisation" described by Myerson is corroborated by the determination of the gel solid as being the crystalline monohydrate form of Phe. The CSP data clearly shows that the structural landscape of Phe is very rich and that all solid forms may not have been characterised yet. The NMR characterisation, coupled to crystallography, clearly shows how the electrostatics of the zwitterionic Phe, coupled to the hydrogen bonding and hydrophobic characteristics, lead to anisotropic assembly and fibre formation. The utilisation of a number of NMR experiments directly on the gel materials shows the significant potential the technique has to completely characterising supramolecular gelation. This includes determining the atomistic details of the packing, and the dynamic behaviour between solid, interface and solutions states of a supramolecular gel material. Finally, we hope that further understanding of the fibre formation by Phe and the atomic structural details of the fibres can lead to research into prevention of Phe aggregation due to phenylketonuria.

\section{Acknowledgements}

Prof. Bill Jones is whole-heartily thanked as host and mentor for GOL, GMD and MDE at Cambridge University while this work was performed. All authors therefore dedicate this manuscript in his honor. GOL and YZK thank the EPSRC Directed Assembly network for funding (EP/K014382/1). GOL thanks the Herchel Smith Fund (Cambridge), Heriot-Watt University and Royal Society of Edinburgh/Scottish Government for funding of fellowships. GMD thanks for the Royal Society for funding of a fellowship and acknowledges the use of the IRIDIS High 
Performance Computing Facility, and associated support services at the University of Southampton, in the completion of this work. We are grateful for financial support from the University of East Anglia through fully funded Ph.D. studentships for KPN and SMR. YZK and KPN acknowledge the use of GRACE High Performance Computing Cluster supported by the Research and Specialist Computing Support service at the University of East Anglia.

\section{ASSOCIATED CONTENT}

Supporting Information. An S.I. file is supplied with complementary data on all aspects of this study and includes crystallography descriptions and analyses, rheology, electron microscopy, NMR and crystal structure prediction. Two crystallographic files are supplied of the single crystal data for the Phe.monohydrate and Phe.hemihydrate forms.

The following files are available free of charge. S.I. (PDF)

\section{REFERENCES}

(1) Adler-Abramovich, L.; Vaks, L.; Carny, O.; Trudler, D.; Magno, A.; Caflisch, A.; Frenkel, D.; Gazit, E. Nat. Chem. Biol. 2012, 8 (8), 701-706.

(2) Do, T. D.; Kincannon, W. M.; Bowers, M. T. J. Am. Chem. Soc. 2015, 137 (32), 1008010083.

(3) Shaham-Niv, S.; Adler-Abramovich, L.; Schnaider, L.; Gazit, E. Sci. Adv. 2015, 1 (7), e1500137.

(4) Singh, V.; Rai, R. K.; Arora, A.; Sinha, N.; Thakur, A. K. Sci. Rep. 2014, 4, 3875.

(5) DePietro, F. R.; Fernstrom, J. D. Brain Res. 1999, 831 (1), 72-84. 
(6) Hsu, W.-P.; Koo, K.-K.; Myerson, A. S. Chem. Eng. Commun. 2002, 189 (8), 1079-1090.

(7) Sato, T.; Sano, C. Method of obtaining phenylalanine anhydrous crystals. EP 0703214 B1, 1995.

(8) Mossou, E.; Teixeira, S. C. M.; Mitchell, E. P.; Mason, S. A.; Adler-Abramovich, L.; Gazit, E.; Forsyth, V. T. Acta Crystallogr. Sect. C Struct. Chem. 2014, 70 (3), 326-331.

(9) Ihlefeldt, F. S.; Pettersen, F. B.; von Bonin, A.; Zawadzka, M.; Görbitz, C. H. Angew. Chem. Int. Ed. 2014, 53 (49), 13600-13604.

(10) King, M. D.; Blanton, T. N.; Korter, T. M. Phys. Chem. Chem. Phys. 2012, 14 (3), 11131116.

(11) Williams, P. A.; Hughes, C. E.; Buanz, A. B. M.; Gaisford, S.; Harris, K. D. M. J. Phys. Chem. C 2013, 117 (23), 12136-12145.

(12) Yuyama, K.; George, J.; Thomas, K. G.; Sugiyama, T.; Masuhara, H. Cryst. Growth Des. 2016, $16(2), 953-960$.

(13) Lu, J.; Wang, J.; Li, Z.; Rohani, S. African J. Pharm. Pharmacol. 2012, 6 (4), 269-277.

(14) Mohan, R.; Koo, K.-K.; Strege, C.; Myerson, A. S. Ind. Eng. Chem. Res. 2001, 40 (26), $6111-6117$.

(15) Khawas, B. Indian J. Phys. A 1985, 58 (3), 219-226.

(16) Khawas, B.; IUCr. Acta Crystallogr. Sect. B Struct. Crystallogr. Cryst. Chem. 1970, 26 (12), 1919-1922. 
(17) Allen, F. H. Acta Crystallogr. B. 2002, 58 (Pt 3 Pt 1), 380-388.

(18) Weissbuch, I.; Frolow, F.; Addadi, L.; Lahav, M.; Leiserowitz, L. J. Am. Chem. Soc. 1990, $112(21), 7718-7724$.

(19) Nonappa, N.; Kolehmainen, E. Soft Matter 2016, 12 (28), 6015-6026.

(20) Nonappa; Lahtinen, M.; Behera, B.; Kolehmainen, E.; Maitra, U. Soft Matter 2010, 6 (8), $1748-1757$.

(21) Weiss, R. G. J. Am. Chem. Soc. 2014, 136 (21), 7519-7530.

(22) Cruz-Cabeza, A.; Day, G.; Jones, W. Chem. - A Eur. J. 2009, 15 (47), 13033-13040.

(23) Cruz-Cabeza, A. J.; Karki, S.; Fábián, L.; Friščić, T.; Day, G. M.; Jones, W. Chem. Commun. 2010, 46 (13), 2224-2226.

(24) Anderson, K. M.; Day, G. M.; Paterson, M. J.; Byrne, P.; Clarke, N.; Steed, J. W. Angew. Chem. Int. Ed. 2008, 47 (6), 1058-1062.

(25) Adams, D. J.; Morris, K.; Chen, L.; Serpell, L. C.; Bacsa, J.; Day, G. M. Soft Matter 2010, $6(17), 4144-4156$.

(26) Piana, F.; Case, D. H.; Ramalhete, S. M.; Pileio, G.; Facciotti, M.; Day, G. M.; Khimyak, Y. Z.; Angulo, J.; Brown, R. C. D.; Gale, P. A. Soft Matter 2016, 12 (17), 4034-4043.

(27) Sheldrick, G. M. Acta Crystallogr. Sect. A Found. Crystallogr. 2008, 64 (1), 112-122.

(28) Barbour, L. J. J. Supramol. Chem. 2001, 1 (4), 189-191. 
(29) Flack, H. D.; IUCr. Acta Crystallogr. Sect. A Found. Crystallogr. 1983, 39 (6), 876-881.

(30) Clark, S. J.; Segall, M. D.; Pickard, C. J.; Hasnip, P. J.; Probert, M. I. J.; Refson, K.; Payne, M. C. Zeitschrift für Krist. 2005, 220, 567-570.

(31) Perdew, J. P.; Burke, K.; Ernzerhof, M. Phys. Rev. Lett. 1996, 77 (18), 3865-3868.

(32) Vanderbilt, D. Phys. Rev. B 1990, 41 (11), 7892-7895.

(33) Pickard, C. J.; Mauri, F. Phys. Rev. B 2001, 63 (24), 245101.

(34) Day, G. M.; S. Motherwell, W. D.; Jones, W. Phys. Chem. Chem. Phys. 2007, 9 (14), 16931704.

(35) Day, G. M.; Cooper, T. G. CrystEngComm 2010, 12 (8), 2443-2453.

(36) Görbitz, C. H.; Dalhus, B.; Day, G. M. Phys. Chem. Chem. Phys. 2010, 12 (30), 8466-8477.

(37) Karfunkel, H. R.; Gdanitz, R. J. J. Comput. Chem. 1992, 13 (10), 1171-1183.

(38) Materials Studio v6.10, Accelrys Software Inc., 2012. .

(39) Coombes, D. S.; Price, S. L.; Willock, D. J.; Leslie, M. J. Phys. Chem. 1996, 100 (18), $7352-7360$.

(40) Cox, S. R.; Hsu, L.-Y.; Williams, D. E.; IUCr. Acta Crystallogr. Sect. A 1981, 37 (3), $293-$ 301.

(41) Williams, D. E.; Cox, S. R.; IUCr. Acta Crystallogr. Sect. B Struct. Sci. 1984, 40 (4), 404 417. 
(42) Stone, A. J.; Alderton, M. Mol. Phys. 2002, 100 (1), 221-233.

(43) Popov, A.; Hickey, M. B.; Hiremath, R.; Peterson, M.; Ratanabanangkoon, P.; Rizzolio, M.; Waggener, S.; Zimenkov, Y. Pharm. Res. 2011, 28 (10), 2556-2566.

(44) Azuri, I.; Meirzadeh, E.; Ehre, D.; Cohen, S. R.; Rappe, A. M.; Lahav, M.; Lubomirsky, I.; Kronik, L. Angew. Chem. Int. Ed. 2015, 54 (46), 13566-13570.

(45) Tahk, D.; Lee, H. H.; Khang, D.-Y. Macromolecules 2009, 42 (18), 7079-7083.

(46) Moggach, S. A.; Marshall, W. G.; Rogers, D. M.; Parsons, S. CrystEngComm 2015, 17 (28), $5315-5328$.

(47) Dunitz, J. D. IUCrJ 2015, 2 (2), 157-158.

(48) Dunitz, J. D.; Gavezzotti, A. J. Phys. Chem. B 2012, 116 (23), 6740-6750.

(49) Braga, D.; Bazzi, C.; Grepioni, F.; Novoa, J. J. New J. Chem. 1999, 23 (6), 577-579.

(50) Braun, D. E.; Nartowski, K. P.; Khimyak, Y. Z.; Morris, K. R.; Byrn, S. R.; Griesser, U. J. Mol. Pharm. 2016, 13 (3), 1012-1029.

(51) Dudek, M. K.; Jeziorna, A.; Potrzebowski, M. J. CrystEngComm 2016, 18 (28), 5267-5277.

(52) Cooper, T. G.; Hejczyk, K. E.; Jones, W.; Day, G. M. J. Chem. Theory Comput. 2008, 4 (10), 1795-1805.

(53) Olsztynska, S.; Dupuy, N.; Vrielynck, L.; Komorowska, M. Appl. Spectrosc. 2006, 60 (9), $1040-1053$. 
(54) Bouguet-Bonnet, S.; Yemloul, M.; Canet, D. J. Am. Chem. Soc. 2012, 134 (25), 1062110627. 


\section{The Plot Thickens, Gelation by Phenylalanine in}

\section{Water and Dimethyl Sulfoxide}

Karol P. Nartowski, Susana M. Ramalhete, Peter C. Martin, Jamie S. Foster, Margaux Heinrich, Mark D. Eddleston, Hayley R. Green, Graeme M. Day, Yaroslav Z. Khimyak* and Gareth O. Lloyd*.

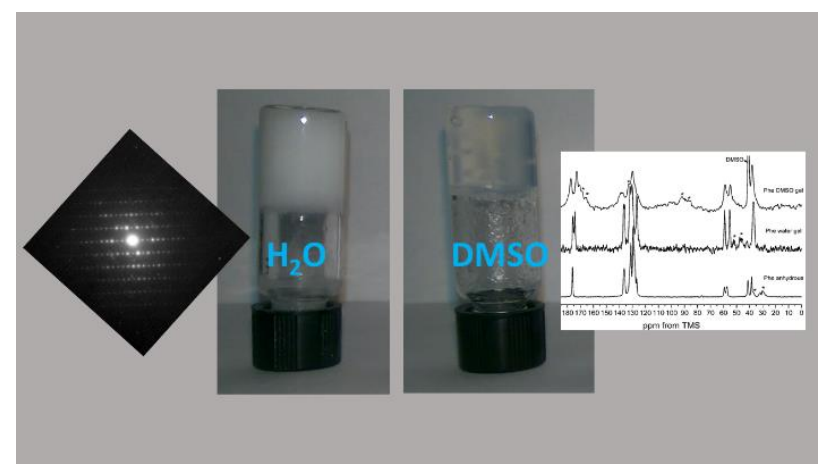

In this report, we highlight the relationship between gelation, crystallisation and the dynamics of the self-assembly processes of Phenylalanine. We do this by describing the gelation and rheology of the amino acid, the gel to crystal relationship, crystal structure predictions for this relatively simple compound, and the dynamics of assembly as determined by NMR in both water and dimethyl sulfoxide. 